\title{
Novel tools for early detection of a global aquatic invasive, the zebra mussel Dreissena polymorpha
}

\author{
ALBA ARDURA $^{\mathrm{a}}$, ANASTASIJA ZAIKO $^{\mathrm{b}, \mathrm{c}}$, YAISEL J. BORRELL ${ }^{\mathrm{d}}$, AURELIJA SAMUILOVIENE $^{\mathrm{b}}$ and \\ EVA GARCIA-VAZQUEZ ${ }^{\mathrm{d}, *}$ \\ ${ }^{a}$ USR3278-CRIOBE-CNRS-EPHE, Laboratoire d'excellence 'CORAIL', Université de Perpignan-CBETM, Perpignan, France \\ ${ }^{\mathrm{b}}$ Marine Science and Technology Centre, Klaipeda University, Klaipeda, Lithuania \\ ${ }^{\mathrm{c}}$ Coastal and Freshwater Group, Cawthron Institute, Nelson, New Zealand \\ ${ }^{\mathrm{d}}$ Department of Functional Biology, University of Oviedo, Oviedo, Spain
}

\begin{abstract}
1. This study presents a species-specific DNA-based marker for detection of the zebra mussel Dreissena polymorpha, recognized as one of the worst invasive species worldwide.

2. The marker was developed in silico and experimentally tested on environmental samples. Gel and capillary electrophoreses for visualization of the PCR products were compared.

3. Marker specificity and sensitivity were assessed in vitro by cross-amplifications and serial dilutions, respectively. The method allows detecting at least $0.7 \mathrm{ng}$ of Dreissena DNA per $\mu \mathrm{L}$ and cross-species amplification was not found in any case.

4. Next-generation sequencing (NGS) metabarcoding (PCR amplification and massive sequencing of a DNA barcode) was used as an independent method for verifying presence of Dreissena DNA molecules in environmental plankton samples collected from the south-eastern Baltic Sea.

5. The consistency between NGS results reporting presence of Dreissena and positive PCR amplification of the marker from the plankton samples confirmed the efficacy of this highly reproducible, fast, cheap and technically easy method.

Copyright (C) 2016 John Wiley \& Sons, Ltd.
\end{abstract}

Received 23 September 2015; Revised 09 February 2016; Accepted 13 March 2016

KEY WORDS: biosecurity; eDNA; metabarcoding; monitoring; invertebrates; alien species

\section{INTRODUCTION}

One of the current widely recognized anthropogenic threats to marine biodiversity is the cross-regional transfer of non-indigenous species (NIS) causing irreversible alterations in communities, habitats and ecosystem functioning (Carlton and Geller, 1993). Early detection of non-indigenous and particularly potentially invasive species is a prerequisite for the efficient and timely response - further spread

*Correspondence to: Eva Garcia-Vazquez, Department of Functional Biology, University of Oviedo, C/ Julian Claveria s/n. 33006 - Oviedo, Spain. Email: egv@uniovi.es 
prevention, eradication (if possible) and mitigation of threats to ecosystems and economy (Olenin et al., 2011; Pochon et al., 2015). However at the early stage of incursion the species is likely to be sparsely distributed in the ecosystem, reducing the chances of detection by routine surveillance methods. On the other hand, the dispersal life stages, such as planktonic eggs or larvae that might be relatively abundant are not identified in traditional zooplankton surveys owing to their cryptic morphology and lack of sufficient specific taxonomical expertise (Neigel et al., 2007; Ardura et al., 2010; Pochon et al., 2013). This poses biosecurity risks, with invasive sessile organisms not being identified until they are already established and widespread and thus difficult to eradicate (Freire et al., 2014; Zaiko et al., 2014).

Among many registered nuisance organisms, the zebra mussel Dreissena polymorpha is recognized as one of the worst invasive species worldwide. For example, in 30 years since zebra mussel was introduced in North America, it has become one of the most widespread and abundant freshwater invertebrates, and has fundamentally transformed freshwater food webs and biogeochemistry. Indeed, few human impacts have been greater or more far-reaching than the arrival of this single species in North American freshwater ecosystems (Strayer, 2009). NIS-related indicators are increasingly included in national and regional legislative initiatives, such as the Marine Strategy Framework Directive (MSFD) (European Commission, 2008) and are a particular focus in various marine monitoring programmes. For example, the abundance and distribution range of the zebra mussel is proposed as a core indicator for the NIS descriptor by the Helsinki Commission (HELCOM, 2013). This urges the development of efficient and reliable methods of species detection, given that benthic zebra mussel populations tend to be temporally and spatially unstable with patchy distribution (Zaiko et al., 2009; Minchin and Zaiko, 2013). Since the traditional surveillance tools seem to be inadequate to detect NIS in aquatic environments when organisms are in low abundance, alternative approaches have been investigated. Several studies have demonstrated the efficacy of environmental DNA (eDNA) coupled with next-generation sequencing of informative regions such as $16 \mathrm{~S}$ rRNA and cytochrome oxidase I gene (COI) as a tool for eukaryote species detection in aquatic environments (Ficetola et al., 2008; Dejean et al., 2011; Jerde et al., 2011; Taberlet et al., 2012; Thomsen et al., 2012; Pochon et al., 2013; Wood et al., 2013). Species-specific molecular markers can be PCR (polymerase chain reaction)-amplified from the eDNA, allowing detection of target organisms such as NIS from early invasion fronts (Jerde et al., 2011), or threatened and indicator species (Thomsen et al., 2012).

The present study focused on the development and validation of species-specific molecular markers for detection of the zebra mussel $D$. polymorpha from environmental (plankton) samples. In addition to the risk of continuing secondary spread of the species within the region there have been recent considerations of using zebra mussel cultivation/harvesting as a complementary measure to control nutrient concentrations in coastal waters (Lindahl et al., 2012; Schernewski et al., 2012). This has enhanced the need for operational surveillance methods aimed at zebra mussel populations and dispersion patterns of their planktonic larvae.

\section{MATERIAL AND METHODS}

\section{Development of a zebra mussel species-specific PCR marker}

Total DNA was extracted employing a method based on silica gel columns (QIAmp DNA Mini kit, Qiagen) from five Dreissena polymorpha adult individuals collected in the Curonian Lagoon (Figure 1), following the manufacturer's instructions. The mussels were identified de visu by taxonomic experts. DNA samples were stored at $4{ }^{\circ} \mathrm{C}$ for immediate follow-up analysis, and aliquots were frozen at $-20^{\circ} \mathrm{C}$ for long-term preservation.

Another five bivalve mollusc species with a planktonic larval stage were sampled from the Lithuanian coast of the Baltic Sea: the native Cerastoderma glaucum, Macoma balthica, Mytilus 


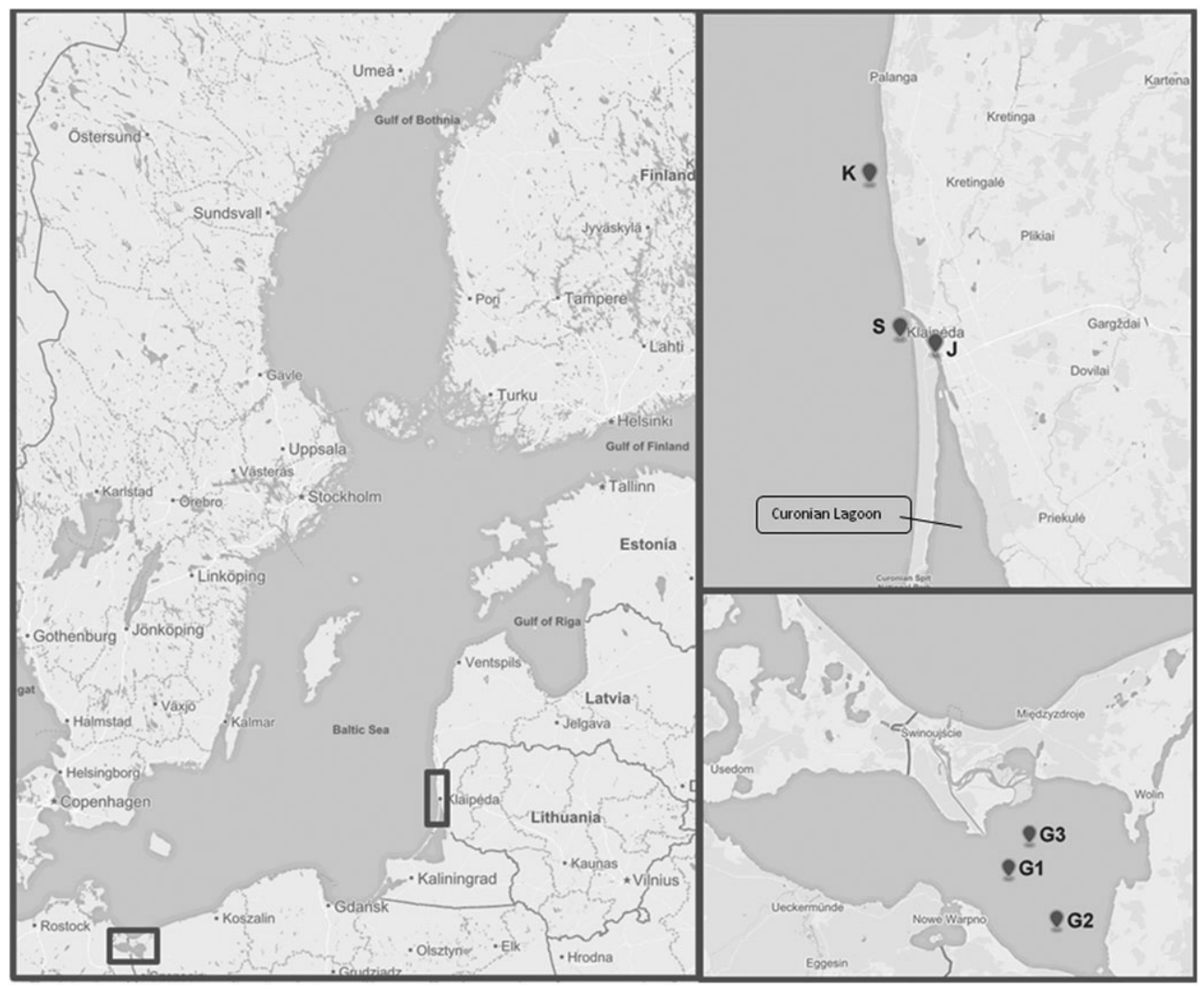

Figure 1. Map of the Baltic Sea with the sampling points analysed in this work.

trossulus; the already established invader Rangia cuneata and the cryptogenic Mya arenaria (the origin of the latter is disputed among scientists, Carlton, 1996). The DNA of these species were extracted the same way as described above. The sequences obtained ( 470 bp long) were submitted to GenBank (www.ncbi.nlm.nih.gov/genbank/) where they are available with the accession numbers KP052743-KP052753, corresponding to C. glaucum, D. polymorpha, four different haplotypes of each of $M$. balthica, $M$. arenaria, $M$. trossulus and three haplotypes of $R$. cuneata. In addition to these sequences, $2516 \mathrm{~S}$ rDNA sequences representative of a wide range of marine taxonomic groups, including algae, invertebrates and vertebrates, were retrieved from GenBank (Table S1, Supplementary material) in order to check the specificity of the new PCR marker.

The 16S rRNA and COI barcode genes were amplified for each of the Dreissena samples. The 16S rRNA was amplified using the primers 16Sar and 16 Sbr described by Palumbi (1996) in a total volume of $20 \mu \mathrm{L}$, with Promega (Madison, WI), Buffer $1 \times, \quad 2.5 \mathrm{mmol} \mathrm{L}^{-1} \mathrm{MgCl}_{2}, \quad 0.25 \mathrm{mmol} \mathrm{L}^{-1}$ dNTPs, 20 pmol of each primer, approximately $20 \mathrm{ng}$ of template DNA and $1 \mathrm{U}$ of DNA Taq polymerase (Promega). The following PCR conditions were applied: initial denaturing at $95^{\circ} \mathrm{C}$ for $5 \mathrm{~min}$, 35 cycles of denaturing at $94^{\circ} \mathrm{C}$ for $1 \mathrm{~min}$, annealing at $55^{\circ} \mathrm{C}$ for $1 \mathrm{~min}$, extension at $72^{\circ} \mathrm{C}$ for $2 \mathrm{~min}$ and final extension at $72^{\circ} \mathrm{C}$ for $7 \mathrm{~min}$. The COI gene fragment was amplified using the primers designed by Geller et al. (2013) in a total volume of $20 \mu \mathrm{L}$ and with a PCR mix containing components and proportions as those described above. The PCR conditions were: initial denaturing at $95^{\circ} \mathrm{C}$ for $5 \mathrm{~min}, 35$ cycles of denaturing at $95^{\circ} \mathrm{C}$ for $1 \mathrm{~min}$, annealing at $48^{\circ} \mathrm{C}$ for $1 \mathrm{~min}$, extension at $72^{\circ} \mathrm{C}$ for $1 \mathrm{~min}$ and final extension at $72^{\circ} \mathrm{C}$ for $5 \mathrm{~min}$.

The PCR products were electrophoresed in a $2 \%$ agarose gel, containing SimplySafe ${ }^{\mathrm{TM}}$ (EURx) and using Promega $100 \mathrm{bp}$ DNA Ladder Molecular Weight Marker for determining the size of the 
amplicons. The same marker served for estimating DNA quantity, by brightness. Bands were purified using the simple protocol of Illustra Exostar 1-Step (GE Healthcare life Sciences) and were then sent to MACROGEN, Amsterdam, Netherlands for sequencing, using a standard Sanger sequencing method (Sanger and Coulson, 1975).

The $D$. polymorpha sequences of COI and $16 \mathrm{~S}$ rRNA genes were aligned using the BioEdit program (Hall, 1999) together with reference sequences of $D$. polymorpha retrieved for each targeted gene from the GenBank. Phylogenetic trees were reconstructed using MEGA version 6 (Tamura et al., 2013) by the method of Neighbour-Joining with the following settings: Tamura-Nei model (Tamura and Nei, 1993) and uniform rates. Robustness of the Neighbour-Joining topology was assessed using 1000 bootstrap replicates.

From the sequence alignments, species-specific primers were designed within each 16S rRNA and COI genes. Regions about 20 nucleotides long were searched within the alignment being invariant within species but different among the species considered. A candidate primer within the alignments was found only for the 16S rRNA gene, since nucleotide regions of the sought characteristics were not found within the COI gene alignment.

\section{Validation of the zebra mussel species-specific PCR marker}

The specificity of the new marker was first validated in silico, by comparing the primers' sequences with the National Center for Biotechnology Information (NCBI, http://www.ncbi.nlm.nih. gov/) database using the basic local alignment search tool (BLAST). BLAST parameters were adjusted to search for short input sequences, the highly similar output sequences were considered to decide on the possibility of cross-reacting with other species.

At the next validation stage, the sensitivity and specificity of the designed primers were experimentally verified. Successive dilutions (1, 1:5, $1: 10,1: 50 ; 1: 100)$ of Dreissena DNA in distilled water were used as templates for PCRs (sensitivity test). Templates containing $70 \mathrm{ng} \mu \mathrm{L}$ of DNA per each of five bivalve species together with $D$. polymorpha successive dilutions $(1,1: 5,1: 10,1: 50$, $1: 100$ ) were used for testing for the potential cross-amplifications with other molluscs co-occurring with $D$. polymorpha in the region (specificity test). The applied PCR conditions were as follows: initial denaturing at $95^{\circ} \mathrm{C}$ for $5 \mathrm{~min}, 35$ cycles of denaturing at $94^{\circ} \mathrm{C}$ for $1 \mathrm{~min}$, annealing at $48^{\circ} \mathrm{C}$ for $1 \mathrm{~min}$, extension at $72^{\circ} \mathrm{C}$ for $2 \mathrm{~min}$ and final extension at $72^{\circ} \mathrm{C}$ for $7 \mathrm{~min}$. The PCR products were electrophoresed in a $1 \%$ agarose gel, containing SimplySafe ${ }^{\mathrm{TM}}$ (EURx) and using Promega 100 bp DNA Ladder Molecular Weight Marker for amplicon size verification and DNA quantification. If no amplifications of the targeted genes were detected by the gel electrophoresis, the PCR was repeated with adjusted conditions (annealing temperatures, number of cycles, DNA concentrations, etc.). Repeatedly unsuccessful amplifications were considered as negative.

Capillary electrophoresis was also used for estimating the amplicon sizes and additional validation tests of all PCR products obtained in the course of the study. For this, only the reverse universal primer, 16br, described by Palumbi (1996) was labelled fluorescently with VIC®. Capillary electrophoresis was performed on ABI 3100 automatic DNA Sequencer and the amplicons were visualized with the PeakScanner Software v1.0, which gives peaks measuring relative fluorescence units (RFU).

\section{Environmental samples and environmental DNA (eDNA) extraction}

For field validation of the designed marker plankton samples from the locations where D. polymorpha could be potentially detected were used. Samples were taken from south-eastern part of the Baltic Sea: the Odra (Szczecin) Lagoon in Poland where an abundant zebra mussel population has been reported (Piesik, 1974; Leppäkoski, 1984; Jansson, 1994; Daunys et al., 2006), the Klaipeda Strait area (Lithuania), where sparse settlements of zebra mussels are observed (Zaiko et al., 2007) and the open Lithuanian coast where Dreissena is not present but planktonic larvae can occasionally 
occur, transported by currents from the stock population in the Curonian Lagoon (Figure 1). The Odra Lagoon samples were considered a natural positive control, owing to the high density of Dreissena polymorpha adults found there (Fenske et al., 2013), and therefore a high concentration of DNA molecules in the water was expected. At other sampling sites (the Klaipeda Strait and Lithuanian coast) none to low abundances of the zebra mussel DNA were expected.

Nine environmental samples were collected covering the presumed spawning season of the zebra mussel between May and August (Sprung, 1993; Garton et al., 2013; and unpublished data from the local surveys). Three samples were obtained from the Odra Lagoon (Stations G1-G3). In the Lithuanian coastal zone, two samples were taken from the Klaipeda Strait area (Station J), three samples from the entrance to the strait from the seaward side (Station S), and one on the open coast, north to the Curonian Lagoon (Station K, Figure 1).

For each sample, a plankton net $(55 \mathrm{~cm}$ diameter, $80 \mu \mathrm{mmesh}$ size) was towed vertically $3-10 \mathrm{~m}$, depending on the depth. The concentrated samples (approximately $10 \mathrm{~mL}$ ) were kept on ice until delivered to the laboratory $(1-4 \mathrm{~h})$, then filtered through $0.12 \mu \mathrm{m}$ NucleporeTM membrane, which was thereafter preserved with $96 \%$ ethanol for future bulk DNA extraction. Total genomic DNA of each sample was extracted using QIAamp ${ }^{\circledR}$ DNA Mini Kit (Qiagen, Germany). DNA extraction was conducted in sterile conditions, inside a laminar air flow chamber disinfected by UV light and absolute ethanol to prevent contamination.

The eDNA samples obtained were used to amplify the $16 \mathrm{~S}$ rRNA region with the designed species-specific primer pairs. Two methods were applied for testing the new primers: (i) unlabelled species-specific primers within the 16S rRNA gene visualized in gel, and (ii) fluorescently labelled specific primers visualized by capillary electrophoresis. For an independent validation of Dreissena detection by species-specific marker, eDNA aliquots from the same samples were analysed using next-generation sequencing (NGS) and a metabarcoding approach.

\section{NGS analysis}

NGS metabarcoding (using cytochrome oxidase gene, COI, as DNA barcode) was employed as an independent method for confirming the presence of the $D$. polymorpha DNA in the environmental samples. The modified universal COI primers (Geller et al., 2013) were used for PCR amplification from the eDNA samples. PCR reactions were undertaken by Macrogen Korea based on the original protocol described by Geller et al. (2013) using blank amplifications as controls for discarding possible contaminations. Library constructions included control steps for sizes (Agilent Technologies 2100 Bioanalyzer using a DNA 1000 chip) and quantity (Roche's Rapid library standard Quantification solution and calculator). Roche's 454 pyrosequencing technology was employed. Later on, the sequence reads were assigned to samples based on their nucleotide barcode (demultiplexing). The software used barcode sequences to segregate the reads from each sample, by matching the initial and final bases of the reads to the known tag sequences used in the preparation of the libraries. Zero base errors were allowed in this sorting by tag step. Quality filtering was also performed at this step, removing any low quality or ambiguous reads.

Pre-processing and clustering was performed by CD-HIT-OTU (Wu et al., 2011). Short reads $(<100$ nucleotides) were filtered out and primers were trimmed. Filtered reads were aligned and clustered at 100\% identity using CD-HIT-DUP. Chimeric reads were identified and eliminated. Secondary clusters were recruited into primary clusters. Sequences of 150 nucleotides or less were removed. Remaining representative reads from non-chimeric sequences were clustered using a greedy algorithm into OTUs at a 97\% cutoff (i.e. at a species level). The OTUs were BLASTed against the NCBI database, with e-value threshold of $0.01, \geq 97 \%$ sequence homology and $>90 \%$ sequence coverage for accepting hits. The OTUs taxonomically assigned to $D$. polymorpha were retained and used as evidence for the presence of the mollusk and for comparison with the new method of detection developed in this work (species-specific marker). 


\section{RESULTS}

\section{Marker design and validation}

The design of species-specific primers was based on the phylogenetic trees obtained for the region with the least intra-specific and most inter-specific variation, in this case in the 16S rRNA gene (Figure 2).

The sequence of the newly designed forward primer is:

DP-16Sar: 5' - TTAAGAGAAATAGCTTAGAA -3'.

Employing the primer 16Sbr described by Palumbi (1996) as a reverse primer together with the new specific forward primer designed, the pair flanks a region of 258 base pairs (bp) (Figure 3).

In silico validation of the new marker resulted in a perfect match of the input sequences $(100 \%$ of query coverage and $100 \%$ of identity) with $D$. polymorpha reference sequences only. The next best hits (with much higher thus less significant e-values) corresponded to reference sequences for Ovis canadensis, Cucumis melo and Solanum lycopersicum. These three species are the bighorn sheep, the melon and the potato, evidently not aquatic species and thus not expected to co-occur with Dreissena, therefore they are not relevant for the purpose of identifying Dreissena from the water samples and can be disregarded.

In vitro assays also confirmed the specificity of the marker. Dreissena-specific primers yielded positive PCR amplifications with one single apparent band (approx. 250 bp) only when D. polymorpha was present in a sample, and never from DNA of other molluscs using the PCR conditions described above. Cross-amplification was thus not found in any case (Figure 3(A)). PCR amplifications from different mixtures of DNA of different molluscs were successful with the new primer only when $D$. polymorpha DNA occurred in the mixture.

The sensitivity test of the marker, performed on different dilutions of $D$. polymorpha DNA, resulted in successful PCR amplifications with clearly visible bands of the expected amplicon size
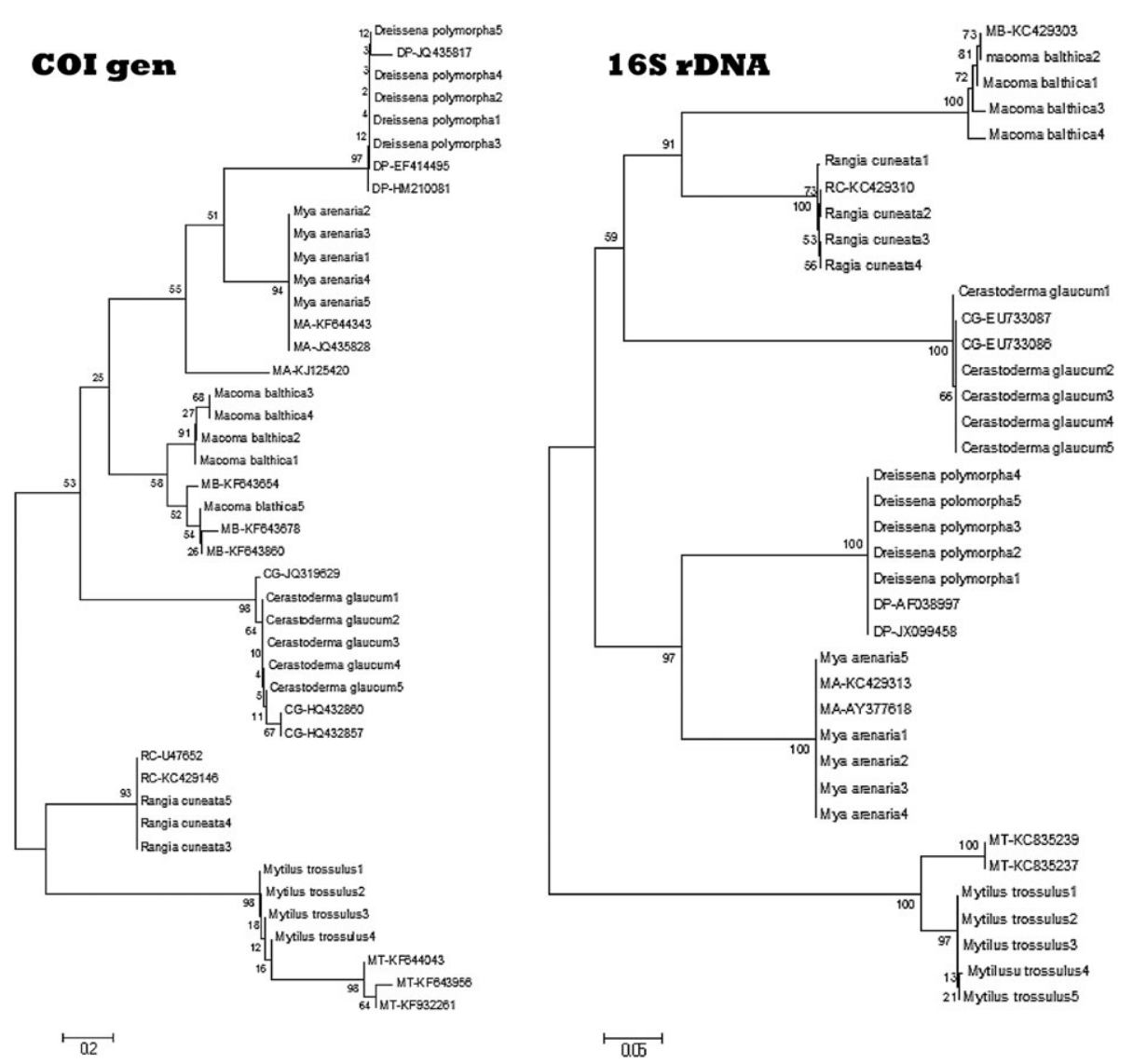

Figure 2. Phylogenetic trees containing the reference and D. polymorpha sequences obtained in this work, for COI and 16S rRNA genes, respectively. 

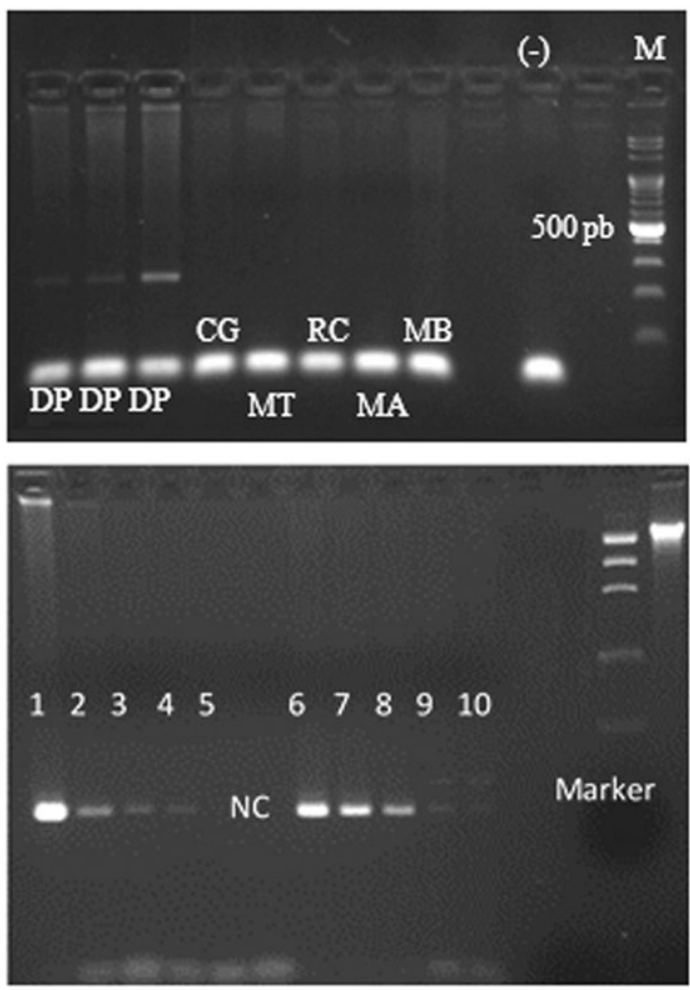

Figure 3. A, above: Agarose gel of PCR products with Dreissenaspecific primers from D. polymorpha (DP), C. glaucum (CG), $M$. trossulus (MT), $R$. cuneata (RC), M. arenaria (MA), $M$. balthica (MB), and NC: negative control. Marker: DNA size marker $100 \mathrm{bp}$ ladder. B, below: Agarose gel of PCR products obtained with Dreissena-specific primers. Left: serial dilutions 1:5 to 1:100 of $D$. polymorpha in distilled water (1-5). Center: $\mathrm{NC}$, negative control. Right: serial dilutions $1: 5$ to $1: 100$ of $D$. polymorpha together with $70 \mathrm{ng} \mu \mathrm{L}^{-1}$ of each of the other five mollusks (6-10). Marker: low DNA mass ladder. DP: D. polymorpha DNA extraction.

for the dilutions assayed down to 1:100 (Figure 3(B)). Hence, the species detection limit could be set at a DNA concentration of $0.7 \mathrm{ng} \mu \mathrm{L}^{-1}$. In experimental DNA mixtures, Dreissena-specific primers exhibited the same sensitivity as for Dreissena DNA alone (1:100). The amplicon was observed at the expected size (258 bp) (Figure 3(B)). It can be concluded that there is no interference when DNA from other co-occurring molluscs is present.

\section{NGS results and species-specific primer validation on environmental samples}

DNA extractions from the nine environmental samples yielded good quality DNA, indicated by nanophotometer absorbance ratios 260/280 ranging between 1.7 and 2.1. The concentration of extracted DNA ranged from 6.3 to $65.7 \mathrm{ng} \mu \mathrm{L}^{-1}$.
The positive PCR amplicons produced a total of 99113 sequences assigned ( $\geq 97 \%$ homology and $>90 \%$ bp coverage) to a species or a genus level. Since the objective of this study was $D$. polymorpha and not the entire biodiversity, only a shallow taxonomic overview will be presented here. Excluding Prokaryotes and Archaeas, 89681 Eukaryote sequences were obtained. The principal taxonomic groups represented by $>100$ sequence reads were Arthropods (64.6\%), Rotifera (22.9\%), Chordata (fish; 7.3\%). Bacillariophyceae (2.2\%), Annelida (1.2\%), Streptophyta and Porifera (0.5\% each), Mollusca (0.4\%) and Ascomycota (0.2\%). A total of 110 sequence reads from that dataset were assigned to D. polymorpha, and appeared in five samples (Table 1): at all three locations within the Odra Lagoon $(61,19,24$ reads at G1, G2, G3, respectively) and in the samples from the Klaipeda Strait area (three reads at both $\mathbf{J} 2$ and $\mathrm{J} 3$ ).

The universal primers (Palumbi, 1996) were used as positive control for DNA quality in the environmental samples, clear and solid bands were obtained demonstrating successful PCR amplification from the nine eDNA samples (Table 1). PCR amplification products obtained with the newly designed specific primers for $D$. polymorpha on eDNA samples were visualized in agarose gel only for the two samples from Odra Lagoon (G1 and G2) (Table 1, Figure 4). For labelled species-specific primers, PCR amplicons of the expected size $(258 \mathrm{bp})$ were clearly visualized in PeakScanner chromatograms (more than 3000 RFU) for the three Odra Lagoon samples (G1, G2 and G3) but not for any of the other samples (Table 1, Figure 5).

\section{DISCUSSION}

This study presents a newly-designed robust species-specific marker that serves for detecting the presence of the global invasive species $D$. polymorpha from environmental samples, even at very low concentrations of the species' DNA. The marker can be fully genotyped in a few hours, requires only minimal technical knowledge, especially if it is visualized in agarose gels (Table 2). Although it may depend on the country, 
Table 1. Results of NGS (number of $D$. polymorpha sequence reads detected with stringent quality filters), PCR amplification with universal primers described by Palumbi (1996) used here as positive amplification controls for eDNA, Dreissena-specific primers described in this article in agarose gel and in automatic DNA sequencer. +: positive and -: negative. In grey shade are the water samples where D. polymorpha DNA was detected by all the methods

\begin{tabular}{|c|c|c|c|c|c|c|c|c|c|}
\hline & \multirow{2}{*}{$\begin{array}{c}\begin{array}{c}\text { LithuaniaNorth to } \\
\text { Curonian Lagoon }\end{array} \\
\mathrm{K}_{1}\end{array}$} & \multicolumn{3}{|c|}{$\begin{array}{l}\text { LithuaniaEntrance to } \\
\text { the strait (sea side) }\end{array}$} & \multicolumn{2}{|c|}{$\begin{array}{l}\text { LithuaniaKlaipeda } \\
\text { strait }\end{array}$} & \multicolumn{3}{|c|}{$\begin{array}{l}\text { PolandOdra } \\
\text { Lagoon }\end{array}$} \\
\hline & & $\mathrm{S}_{1}$ & $\mathrm{~S}_{2}$ & $\mathrm{~S}_{3}$ & $\mathbf{J}_{2}$ & $\mathrm{~J}_{3}$ & $\mathrm{G}_{1}$ & $\mathrm{G}_{2}$ & $\mathrm{G}_{3}$ \\
\hline $\begin{array}{l}\text { Number of reads of Dreissena } \\
\text { polymorpha NGS sequences } \\
\text { (Proportion of sequence reads } \\
\text { assigned to Dreissena, \% of the total } \\
\text { number of sequence reads } \\
\text { in sample) }\end{array}$ & $0(0)$ & $0(0)$ & $0(0)$ & $0(0)$ & $3(0.119)$ & $3(0.048)$ & $61(0.813)$ & $19(1.225)$ & $24(0.159)$ \\
\hline $\begin{array}{l}\text { PCR amplification with Palumbi } \\
\text { primers (Palumbi, 1996) }\end{array}$ & + & + & + & + & + & + & + & + & + \\
\hline $\begin{array}{l}\text { PCR amplification with Dreissena- } \\
\text { specific primers visualized in } \\
\text { agarose gel }\end{array}$ & - & - & - & - & - & - & + & + & - \\
\hline $\begin{array}{l}\text { PCR amplification with labelled } \\
\text { Dreissena-specific primers as } \\
\text { visualized in automatic DNA } \\
\text { sequencer }\end{array}$ & - & - & - & - & - & - & + & + & + \\
\hline
\end{tabular}

laboratory and/or company, at present (2015) the estimated cost would be $5-10 €$ per sample, or less if it is automated. The process is the same for tissue and water samples, with the only difference of an extra step of water filtration in the latter case.

These characteristics would suggest the use of this marker for early detection of D. polymorpha and further surveillance of the established populations. The tools used in the early detection and monitoring of invasive species need to be rapidly deployable, cost-effective, technically accessible, and accurate (Darling and Blum, 2007). In the traditional approaches these criteria are not well met because taxonomists with expertise in multiple taxa are needed for identification of

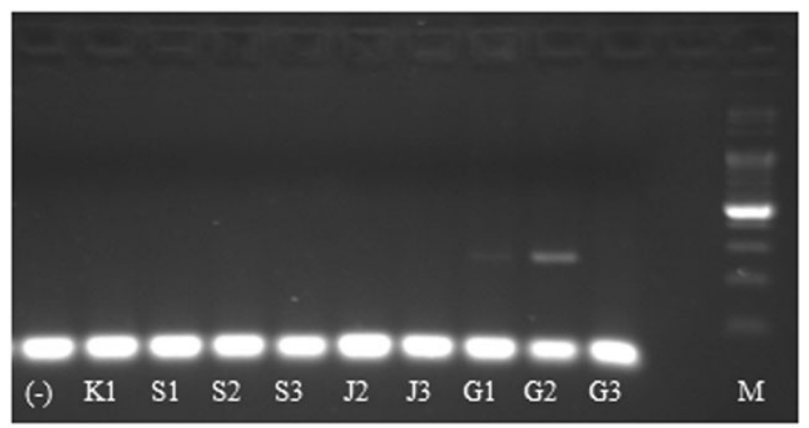

Figure 4. Agarose gel with PCR products obtained with Dreissenaspecific primers from Baltic water samples, as $\mathrm{K}_{1}$ (Lithuanian coast); $\mathrm{S}_{1}, \mathrm{~S}_{2}, \mathrm{~S}_{3}$ (entrance to the Klaipeda Strait from the sea side); $\mathrm{J}_{2}, \mathrm{~J}_{3}$ (Klaipeda Strait). complex communities, thus significantly increasing the costs of surveillance (Lawton et al., 1998). In addition, some taxa or particular life stages can be very difficult to detect and unambiguously identify. In the case with D. polymorpha, it has a pelagic larval stage easily confounded with other mollusc larvae. The marker developed here can aid detection of the species from water samples and allows instant results retrieved within one working day at a reasonable price.

Similar approaches (application of the speciesspecific molecular markers on eDNA samples) can be adapted for detecting other species of interest (invasive, indicator, threatened, etc.). There are, however, some considerations to be taken into account before suggesting such tools for routine surveillance of the target organisms. First, the DNA region of choice must anneal on every individual of the target species. In this work, although the NGS validation was performed with cytochrome oxidase I (COI) since comprehensive collection of the reference sequences is available in databases for this marker (Hebert et al., 2003), the specific primer was designed within the 16S rRNA region because the intra-specific variation is lower in this gene (Figure 2).

Second, the marker must be species-specific to ensure consistent species detection (Diaz-Ferguson et al., 2014). In the present study, no cross- 

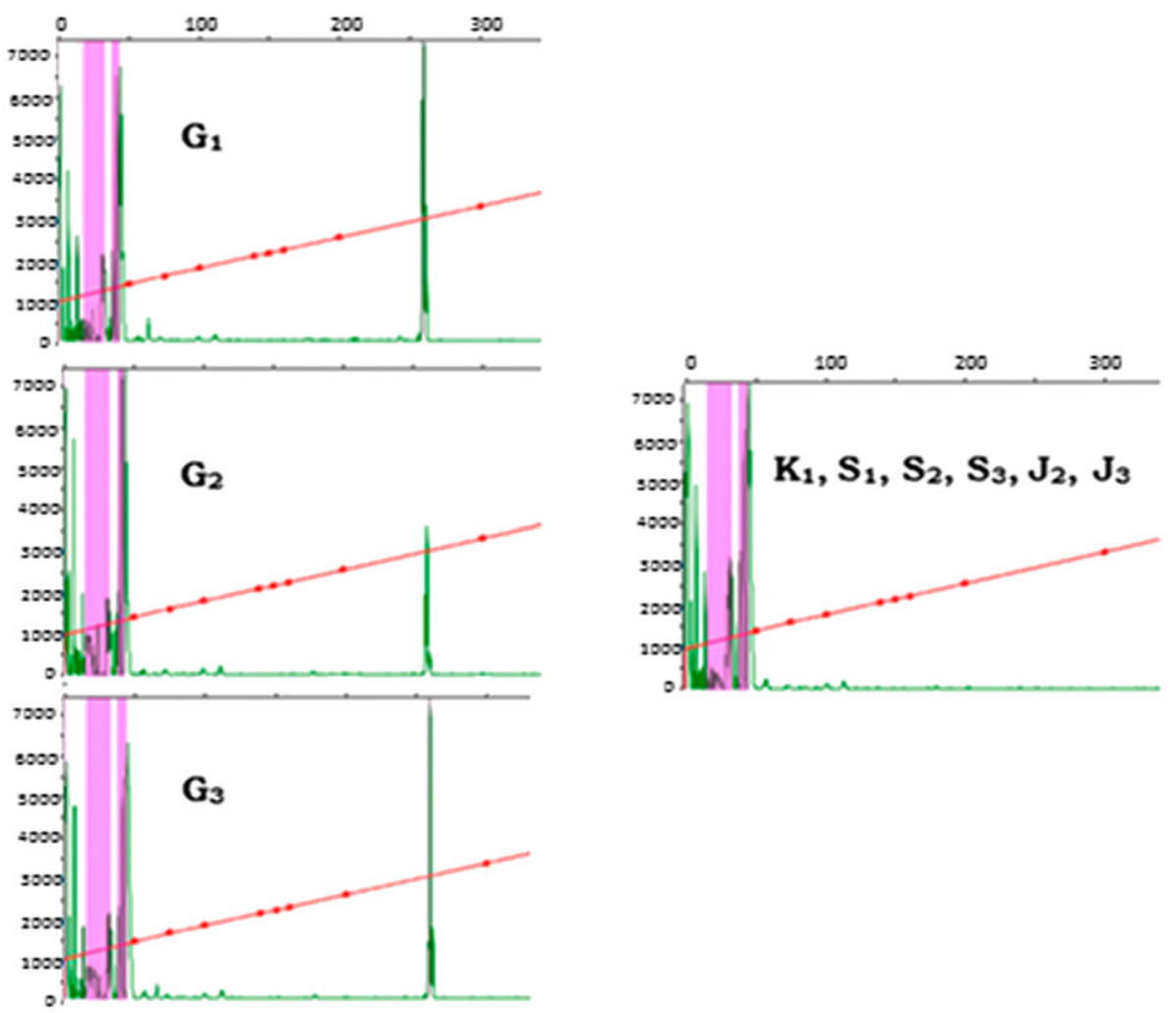

Figure 5. Visualization of fluorescently labelled amplicons with PeakScanner. Clear positive amplicons were observed for the three samples obtained from Odra Lagoon $\left(\mathrm{G}_{1}, \mathrm{G}_{2}\right.$ and $\left.\mathrm{G}_{3}\right)$ and none for the rest of the sampling points ( $\mathrm{K}_{1}$ (Lithuanian Coast); $\mathrm{S}_{1}, \mathrm{~S}_{2}, \mathrm{~S}_{3}$ (entrance to the Klaipeda Strait from the sea side); $\mathbf{J}_{2}, \mathbf{J}_{3}$ (Klaipeda Strait)).

amplification with other aquatic species that could occur in the same environment was detected (Figure 3(a)), as also confirmed by the in silico tests. However, before applying the same markers in other ecosystems the cross-amplification tests should be conducted involving the local closely related organisms.

Third, the threshold of detection is very important, particularly if the species-specific primers are considered for early detection of NIS. At the early stage of incursion non-indigenous organisms are expected to be at very low densities and sparsely distributed. Here the marker yielded PCR amplification with visible amplicons at low DNA concentrations (Table 1, Figure 5) thus allowing species' detection from a few cells in a sample. Indeed, NGS-based methodology is also capable of species detection and is highly sensitive,

Table 2. Time and technical difficulty of the proposed Dreissena-specific marker

\begin{tabular}{|c|c|c|c|c|}
\hline & Activity & Equipment required & Technical difficulty & Time \\
\hline Step 2 & PCR amplification & Medium (thermal cycler) & Easy & $\begin{array}{l}2-4 \mathrm{~h} \text { (depending on } \\
\text { cycles) }\end{array}$ \\
\hline Step 3-a & $\begin{array}{l}\text { Separation by electrophoresis in } \\
\text { agarose gel }\end{array}$ & $\begin{array}{l}\text { Basic (electrophoresis cuvettes, electricity } \\
\text { supply) }\end{array}$ & Easy & $20 \mathrm{~min}$ \\
\hline Step 3-b & $\begin{array}{l}\text { Separation by capillary } \\
\text { electrophoresis }\end{array}$ & $\begin{array}{l}\text { Medium (automated sequencer such as ABI } \\
\text { Prism or similar) }\end{array}$ & $\begin{array}{l}\text { Medium (can be } \\
\text { externalized) }\end{array}$ & $\begin{array}{l}\text { Depending on system } \\
-<1 \mathrm{~h}\end{array}$ \\
\hline
\end{tabular}


but the cost of the sequencing is significantly higher and substantial analytical effort (bioinformatics) is needed to ensure efficient exploration of sequence data obtained from the multi-species communities (Blanchet, 2012). In this work, consistent results in detection of Dreissena were obtained using NGS and the newly developed specific marker from water samples from the Odra Lagoon (samples G). In water samples from the Klaipeda Strait (J2 and J3), the number of reads detected by NGS was really low (=3) and would be generally eliminated from the assigned species list after applying more stringent OTU-picking filters (Bokulich et al., 2013). The use of capillary electrophoresis for detecting amplicons of the newly developed marker could be recommended for more precise detection of $D$. polymorpha from environmental samples. This is supported by the higher consistency observed between results obtained by this method and those obtained by NGS. On the other hand, NGS might underestimate the presence of the species as well, owing to the relatively reduced performance of primers employed here, since in standard assays they registered only 54\% success in Bivalvia (Geller et al., 2013). Notwithstanding this, the comparison between locations is still valid because the bias, if occurring, would be the same in all samples.

Another advantage of the new marker is that the target fragment is very short (258 bp) and can be PCR amplified even in partly degraded DNA with further visualization in agarose gel. This is very important for species detection from environmental samples because short DNA fragments can persist in the environment for a longer time than the large fragments and thus report the 'recent biodiversity' rather than the actual one. For instance, it was proven that DNA fragments of approximately $400 \mathrm{bp}$ may persist for up to one week at $18^{\circ} \mathrm{C}$ in lake water (Matsui et al., 2001). This is particularly important for target species detection from plankton samples because of the dynamic and unstable nature of the plankton communities.

Since environmental samples can contain cells or tissues of the species suspended in the water column (Minamoto et al., 2012; Diaz-Ferguson et al., 2014), use of eDNA for species detection appears a promising tool and can be incorporated into surveillance and management programmes related to conservation and early detection/rapid response actions (Diaz-Ferguson et al., 2014). For the zebra mussel cultivation-related studies, the markers can be used for the rapid screening of spatial-temporal patterns of larvae dispersal and assigning suitable areas and/or timing for deployment of cultivation facilities. In summary, the molecular tools presented here are technically accessible and will facilitate the monitoring of zebra mussel populations at a minimal cost.

\section{ACKNOWLEDGEMENTS}

This study has been supported by the Spanish Grant MINECO CGL-2013-42415-R and by BONUS (Art 185) project BaltCoast funded jointly by the EU 7th Framework Programme and Research Council of Lithuania and the Research Council of Lithuania project BALMAN (project no. TAP-LLT-14-013). We thank Diana Vaičiūte for help with environmental samples collection and Lithuanian EPA Marine Research Department for providing the samples of bivalve molluscs. This is a contribution from the Marine Observatory of Asturias. A.A. holds a regional postdoctoral Marie Curie grant COFUND-CLARIN.

\section{REFERENCES}

Ardura A, Linde AR, Moreira JC, Garcia-Vazquez E. 2010. DNA barcoding for conservation and management of Amazonian commercial fish. Biological Conservation 143: 1438-1443.

Blanchet S. 2012. The use of molecular tools in invasion biology: an emphasis on freshwater ecosystems. Fisheries Management and Ecology 19: 120-132.

Bokulich NA, Subramanian S, Faith JJ, Gevers D, Gordon JI, Knight R, Mills DA, Caporaso JG. 2013. Quality-filtering vastly improves diversity estimates from Illumina amplicon sequencing. Nature Methods 10: 57-59.

Carlton JT. 1996. Biological invasions and cryptogenic species. Ecology 77: 1653-1655.

Carlton JT, Geller JB. 1993. Ecological roulette: the global transport of non-indigenous marine organisms. Science 261: 78-82.

Darling JA, Blum MJ. 2007. DNA-based methods for monitoring invasive species: a review and prospectus. Biological Invasions 9: 751-765.

Daunys D, Zemlys P, Olenin S, Zaiko A, Ferrarin C. 2006. Impact of the zebra mussel Dreissena polymorpha invasion on the budget of suspended material in a shallow lagoon ecosystem. Heligoland Marine Research 60: 113-120. 
Dejean T, Valentini A, Duparc A, Pellier-Cuit S, Pompanon F, Taberlet P, Miaud C. 2011. Persistence of environmental DNA in freshwater ecosystems. PloS One 6(8): e23398.

Diaz-Ferguson E, Herod J, Galvez J, Moyer G. 2014. Development of molecular markers for eDNA detection of the invasive African jewelfish (Hemichromis letourneuxi): a new tool for monitoring aquatic invasive species in National Wildlife Refuges. Management of Biological Invasions 5: 121-131.

European Commision 2008. Directive 2008/56/EC of the European Parliament and of the Council establishing a framework for community action in the field of marine environmental policy (Marine Strategy Framework Directive). The Official Journal of European Union L164: 19-40.

Fenske C, Zaiko A, Wozniczka A, Dahlke S, Orlova MI. 2013. Variation in length-frequency distributions of zebra mussels (Dreissena polymorpha) within and between three Baltic Sea subregions Szczecin Lagoon, Curonian Lagoon, and Gulf of Finland. In Quagga and Zebra Mussels: Biology, Impacts and Control, Nalepa TF, Schlosser DW (eds). CRC Press, Taylor and Francis Group: Boca Raton, FL; 725-740.

Ficetola GF, Miaud C, Pompanon F, Taberlet P. 2008. Species detection using environmental DNA from water samples. Biological Letters 4: 423-425.

Freire M, Genzano GN, Neumann-Leitao S, Perez CD. 2014. The non-indigenous medusa Blackfordia virginica (Hydrozoa, Leptothecata) in tropical Brazil: 50 years of unnoticed presence. Biological Invasions 16: 1-5.

Garton DW, McMahon R, Stoeckmann AM. 2013. Limiting environmental factors and competitive interactions between zebra and quagga mussels in North America. In Quagga and Zebra Mussels: Biology, Impacts and Control, Nalepa TF, Schlosser DW (eds). CRC Press, Taylor and Francis Group: Boca Raton, FL; 383-402.

Geller J, Meyer C, Parker, M, Hawk H. 2013. Redesign of PCR primers for mitochondrial cytochrome $\mathrm{c}$ oxidase subunit I for marine invertebrates and application in all taxa biotic surveys. Molecular Ecology Resources 13: 851-861.

Hall A. 1999. BioEdit: a user-friendly biological sequence alignment editor and analysis program for Windows 95/98/ NT. Nucleic Acids Symposium Series 41: 95-98.

Hebert PD, Cywinska A, Ball SL. 2003. Biological identifications through DNA barcodes. Proceedings of the Royal Society of London B: Biological Science 270: 313-321.

Helcom. 2013. HELCOM core indicators: Final report of the HELCOM CORESET project. Baltic Sea Environment Proceedings 136: 74.

Jansson K. 1994. Alien species in the marine environment. Introductions to the Baltic Sea and Swedish west coast. Swedish Environmental Agency Report 4357: 1-68.

Jerde CL, Mahon AR, Chadderton WL, Lodge DM. 2011. 'Sight-unseen' detection of rare aquatic species using environmental DNA. Conservation Letters 4: 150-157.

Lawton JH, Bignell DE, Bolton B, Bloemers GF, Eggleton P, Hammond PM, Hodda M, Holt RD, Larsen TB, Mawdsley NA, et al. 1998. Biodiversity inventories, indicator taxa and effects of habitat modification in tropical forest. Nature 391: 72-76.

Leppäkoski E. 1984. Introduced species in the Baltic Sea and its coastal ecosystems. Ophelia Supplement 3: 123-135.
Lindahl O, Zaiko A, Cahill B. 2012. Mussel cultivation. In Submariner Compendium: An Assessment of Innovtive and Sustainable Uses of Baltic Marine Resources, SchultzZehden A, Matczak M (eds). Maritime Institute in Gdańsk; 77-102.

Matsui M, Honjo M, Kawabata Z. 2001. Estimation of the fate of dissolved DNA in thermally stratified lake water from the stability of exogenous plasmid DNA. Aquatic Microbial Ecology 26: 95-102.

Minamoto T, Yamanaka H, Takahara T, Honjo M, Kawabata Z. 2012. Surveillance of fish species composition using environmental DNA. Limnology 13: 193-197.

Minchin D, Zaiko A. 2013. Variability of the zebra mussel (Dreissena polymorpha) impacts in the Shannon River system. In Quagga and Zebra Mussels: Biology, Impacts and Control, Nalepa TF, Schlosser DW (eds). CRC Press, Taylor and Francis Group: Boca Raton, FL; 587-597.

Neigel J, Domingo A, Stake J. 2007. DNA barcoding as a tool for coral reef conservation. Coral Reefs 26: 487-499.

Olenin S, Elliott M, Bysveen I, Culverhouse PF, Daunys D, Dubelaar, GB, Vandekerkhove J. 2011. Recommendations on methods for the detection and control of biological pollution in marine coastal waters. Marine Pollution Bulletin 62: 2598-2604.

Palumbi SR. 1996. Nucleic acids II: the polymerase chain reaction. In Molecular Systematic, Hillis DM, Moritz C, Mable BK (eds). Sinauer Associates; 205-247.

Piesik Z. 1974. The role of the crayfish Orconectes limosus (Raf,) in Extinction of Dreissena polymorpha (Pall.) subsisting on Steelon-Net. Polskie Archiwum Hydrobiologii 1: 401-410.

Pochon X, Bott NJ, Smith LF, Wood SA. 2013. Evaluating detection limits of Next-Generation Sequencing for the surveillance and monitoring of international marine pests. PloS One 8: e73935.

Pochon X, Atalah J, Wood SA, Hopkins GA, Watts A, Boedeker C. 2015. Cladophora ruchingeri (C. Agardh) Kützing, 1845 (Cladophorales, Chlorophyta): a new biofouling pest of green-lipped mussel Perna canaliculus (Gmelin, 1791) farms in New Zealand. Aquatic Invasions 10: $123-133$.

Sanger F, Coulson AR. 1975. A rapid method for determining sequences in DNA by primed synthesis with DNA polymerase. Journal of Molecular Biology 94: 441-448.

Schernewski G, Stybel N, Neumann T. 2012. Zebra mussel farming in the Szczecin (Oder) Lagoon: water-quality objectives and cost-effectiveness. Ecology and Society 17: 4.

Sprung M. 1993. The other life: an account of present knowledge of the larval phase of Dreissena polymorpha. In Zebra Mussels: Biology, Impacts, and Control, Nalepa TF, Schloesser DW (eds). Lewis Publishers, CRC Press: Boca Raton, FL; 39-53.

Strayer DL. 2009. Twenty years of zebra mussels: lessons from the mollusk that made headlines. Frontiers in Ecology and the Environment 7: 135-141.

Taberlet P, Coissasc E, Hajibabei M, Rieseberg LH. 2012. Environmental DNA. Molecular Ecology 21: 1789-1793.

Tamura K, Nei M. 1993. Estimation of the number of nucleotide substitutions in the control region of mitochondrial DNA in humans and chimpanzees. Molecular Biology and Evolution 10: 512-526. 
Tamura K, Stecher G, Peterson D, Filipski A, Kumar S. 2013. MEGA6: molecular evolutionary genetics analysis version 6.0. Molecular Biology and Evolution 30: 2725-2729.

Thomsen PF, Kielgast J, Iversen LL, Moller PR, Rasmussen M, Willerslev E. 2012. Detection of a diverse marine fish fauna using environmental DNA from seawater samples. PLOS ONE 7: e41732.

Wood SA, Smith KF, Banks JC, Tremblay LA, Rhodes L, Mountfort D, Cary SC, Pochon X. 2013. Molecular genetic tools for environmental monitoring of New Zealand's aquatic habitats, past, present and the future. New Zealand Journal of Marine and Freshwater Research 47: $90-119$.

Wu S, Zhu Z, Fu L, Niu B, Li W. 2011. 'WebMGA: a Customizable Web Server for Fast Metagenomic Sequence Analysis'. BMC Genomics 12: 444.

Zaiko A, Olenin S, Daunys D, Nalepa TF. 2007. Vulnerability of benthic habitats to the aquatic invasive species. Biological Invasions 9: 703-714.
Zaiko A, Daunys D, Olenin S. 2009. Habitat engineering by the invasive zebra mussel Dreissena polymorpha (Pallas) in a boreal coastal lagoon: impact on biodiversity. Helgoland Marine Research 63: 85-94.

Zaiko A, Minchin D, Olenin S. 2014. 'The day after tomorrow': anatomy of an ' $r$ ' strategist aquatic invasion. Aquatic Invasions 9: 145-155.

\section{SUPPORTING INFORMATION}

Additional supporting information may be found in the online version of this article at the publisher's web site.

Table S1. 16S rDNA sequences representative of a wide range of marine taxonomic groups, including algae, invertebrates and vertebrates retrieved from GenBank 